\title{
New antimicrobial peptides purified directly from Bullacta exarata
}

\author{
Ma Jian-yin ${ }^{1 *}$, Guo Xiao-mian², Hu Jun-feng ${ }^{1}$ and Wang Xian ${ }^{1}$ \\ ${ }^{1}$ School of Food and Pharmacy, Zhejiang Ocean University, Zhoushan, Zhejiang, 316004, China. \\ ${ }^{2}$ Hangzhou Wanxiang Polytechnic, Hangzhou, Zhejiang, 310023, China.
}

Accepted 29 August, 2011

\begin{abstract}
Endogenous antimicrobial peptides are exciting candidates as new antibacterial agents due to their broad antimicrobia spectra, highly selective toxicities and the difficulty for bacteria to develop resistance to these peptides. Marine invertebrates, which rely solely on innate immune system for host defense, are the spectacular resources for new antimicrobial compounds. In order to seek for new effective antibiotics, tissue homogenate of Bullacta exarata was treated with trypsin, and was isolated following ultrafiltration, gel chromatography and reverse phase high performance liquid chromatography (reverse-phase HPLC). Antibacterial activities of the peptides purified from $B$. exarata were measured by the agar diffusion test and minimal inhibitory concentration (MIC). Three isolated peptides, BEP-1, BEP-2 and BEP-3, showed activity against Escherichia coli, Staphylococcus aureus and Bacillus subtilis. BEP-1 also showed activity against human pathogen strains (Staphylococcus epidermidis, E. coli and Methecillin-Resistant S. aureus). This research picked out three candidates for new effective antibiotics.
\end{abstract}

Key words: Bullacta exarata, antimicrobial peptides, isolation and purification, antibacterial activity, minimal inhibitory concentration.

\section{INTRODUCTION}

Antimicrobial peptides are small peptides existing widely in mammals, amphibians, marine invertebrates and insects, and they appear to be one of the actors in innate immunity. As a component of the innate immune defense system, these peptides are mainly located in epithelia or circulating cells. Antimicrobial peptides are not only the potent, broad spectrum antibiotics, but also an important factor contributing to self-defense system against invading microorganisms, mediating humoral immunity (Bulet et al., 2004). In addition, these peptides have been demonstrated to kill fungi, viruses and cancerous cells (Brogden et al., 2003; Chen et al., 2003). Antimicrobial peptides are also characterized as soluble in water, cationic, amphiphilic, better resistant to heat, etc.

Recently, a number of antimicrobial peptides have been isolated from organisms such as plants, insects, marine invertebrates and vertebrates including human being.

*Corresponding author. E-mail: wingsing99@126.com. Tel: (86)580-2555280.
And there have been preliminary works on mechanism of their antimicrobial activities. These peptides, generally act by disrupting membrane integrity and interfering with metabolism (Epand and Epand, 2000; Michael, 2003). The contact between cationic antimicrobial peptides and negatively charged lipid membranes of bacteria transfers cationic charge to the membrane, depolarizing the bacterial membrane and disrupting the normal array of membrane lipid bilayer. In addition, this allows the peptides insert into membrane lipid bilayer to form pores, causing outflow of intracellular potassium ion and finally cell death.

Bullacta exarata is a species of a sea snail, a marine gastropod mollusc in the family Haminoeidae. It is composed of a shell and a soft body. B. exarata is abundant in coastlines of the China Seas from Hainan to Yellow Sea in eastern China. The habitat for $B$. exarata includes intertidal flats, including the supratidal zone and subtidal zone.

There is appearance of a growing number of bacteria resistant to conventional antibiotics, forcing the development of antibiotics with novel mechanisms. Endogenous 
Table 1. Diameters of zone of inhibition of extracts from $B$. exarata $(\mathrm{mm})(\overline{\mathrm{x}} \pm \mathrm{SD}, \mathrm{n}=3)$.

\begin{tabular}{lcccc}
\hline Type of strain & Part A & Part B & Part C & Part D \\
\hline S. aureus & $1.5 \pm 0.2$ & $5.1 \pm 0.3$ & $0.2 \pm 0.1$ & $4.2 \pm 0.5$ \\
E. coli & $2.8 \pm 0.5$ & $4.0 \pm 0.4$ & 0 & $2.0 \pm 0.3$ \\
B. subtilis & $2.0 \pm 0.4$ & $4.0 \pm 0.3$ & 0 & $2.2 \pm 0.3$ \\
\hline
\end{tabular}

The antimicrobial activity was measured by agar diffusion test. The larger diameter means the more antimicrobial activity.

antimicrobial peptides are considered as exciting candidates due to their broad activity spectrum and the difficulty for bacteria to develop resistance to them (Hancock and Scott, 2000; Lehrer and Ganz, 1999). Marine invertebrates that rely solely on innate immune mechanisms for host defense, as a result, become spectacular resources for the development of new antimicrobial compounds. Here, we purified three novel antimicrobial peptides directly from the body of $B$. exarata for the first time. We also studied their activity spectrum searching for their possible utility as new antimicrobial compounds.

\section{MATERIALS AND METHODS}

\section{Peptide extractions}

$B$. exarata were obtained from a commercial shellfish farm (Mamu Farm, Zhoushan in Zhejiang Province). The meat of $B$. exarata was homogenized by high-speed tissue-masher. After being added about $0.5 \%$ trypsin (Sinopharm Chemical Reagent Co. Ltd, China) and adjusted to $\mathrm{pH} 8.7$, this tissue homogenate was then incubated for $8 \mathrm{~h}$ at $45^{\circ} \mathrm{C}$ and treated for $30 \mathrm{~min}$ at $100^{\circ} \mathrm{C}$. Debris were eliminated by centrifugation $\left(11000 \mathrm{~g}, 20 \mathrm{~min}, 4^{\circ} \mathrm{C}\right)$. The supernatant was separated by ultrafiltration with three types of ultrafiltration membrane $(10,5$ and $3 \mathrm{kD})$ into four parts, which were lyophilized and kept at $-20^{\circ} \mathrm{C}$ until use.

\section{Purification}

The active lyophilized supernatant ( 5 to $10 \mathrm{kD}$ ) was reconstituted with $3 \mathrm{ml}$ water, and loaded onto Sephadex G-50 cartridge $(2.6 \times$ $100 \mathrm{~cm}$, Pharmacia). Eluting with water, the effluent was monitored by UV absorption at $280 \mathrm{~nm}$. The fractions obtained were lyophilized, reconstituted and tested for antimicrobial activity as described subsequently. The active lyophilized fraction was reconstituted with water, and submitted to reverse-phase HPLC (P1201, Dalian Elite Analytical Instruments Co., Ltd).

Aliquots of $0.2 \mathrm{ml}$ of the active fraction were subjected to reversephase HPLC on a Kromasil100-10 $\mathrm{C}_{18}$ column $(10 \times 250 \mathrm{~mm}$, Akzo Nobel) right after equilibrating the column with $0.05 \%$ trifluoroacetic acid (TFA) in water. Elution was performed with acetonitrile containing $0.05 \%$ TFA, and monitored by UV absorption at $254 \mathrm{~nm}$. All HPLC purification steps were carried out at a flow rate of 1.0 $\mathrm{ml} / \mathrm{min}$. The HPLC purification was monitored by UV absorption at $254 \mathrm{~nm}$. The fractions obtained were tested for antimicrobial activity.

\section{Micro-organisms}

For experimental use, the bacteria of Escherichia coli and
Staphylococcus aureus were offered by NIFDC (National Institutes for Food and Drug Control). Bacillus subtilis was offered by ZheJiang Institutes for Food and Drug Control. The human pathogen strains, Staphylococcus epidermidis, E. coli and Methecillin-Resistant $S$. aureus (MRSA) were isolated from patients by ZhouShan Hospital.

\section{Antimicrobial assays}

After incubation on Mueller Hinton agar (Aoboxing Biotech, China) at $37^{\circ} \mathrm{C}$ for 18 to $20 \mathrm{~h}$, bacteria monoclons were incubated in Mueller Hinton broth medium (BBI) and quantified by counting. This incubation was not stopped until the concentration was about $10^{8}$ $\mathrm{CFU} / \mathrm{ml}$

The agar diffusion test (Kirby-Bauer disk-diffusion method) (Wei et al., 2010) was used to distinguish antimicrobial parts in extraction. The culture plate was coated with Mueller Hinton agar, and then swabbed uniformly with broth agar containing tested bacteria. A filter-paper disk, impregnated with tested part of extraction $(5 \mathrm{mg} / \mathrm{ml})$, was then placed on the surface of the agar. The size of zone of inhibition was measured after $24 \mathrm{~h}$ incubation at $37^{\circ} \mathrm{C}$. The diameter of zone of inhibition was expressed as a diameter (average the readings by three separate times) for the area around the filter disk.

The antimicrobial activities of peptides purified by HPLC were determined by measuring the minimal inhibitory concentration (MIC). Serial doubling dilutions of peptides were made in $0.9 \%$ $\mathrm{NaCl}$. Two-millilitre aliquots from each dilution were incubated in culture plates with $2 \mu \mathrm{l}$ of suspension of bacteria (containing $10^{3}$ to $10^{4} \mathrm{CFU}$ ) in $18 \mathrm{ml}$ Mueller Hinton broth medium. The ultimate concentrations were $5,10,20,40,80,160 \mathrm{ggml}^{-1}$ peptides, with ampicillin as control. After 18 to $24 \mathrm{~h}$ incubation at $37^{\circ} \mathrm{C}$, the MIC values were expressed as the highest peptide concentration that causes $100 \%$ growth inhibition. The $\mathrm{MIC}_{50}, \mathrm{MIC}_{90}$ and cumulative inhibitory rate of peptides against human pathogen strains were also given (Wei et al., 2010).

\section{RESULTS}

\section{Antimicrobial extracts isolated directly from the meat of $B$. exarata}

The supernatant of the tissue homogenate treated with trypsin was separated by ultrafiltration, and resulted to be Part A (proteins larger than $10 \mathrm{kD}$ ), Part B (proteins between 5 to $10 \mathrm{kD}$ ), Part $C$ (proteins between 3 to $5 \mathrm{kD}$ ) and Part D (proteins smaller than $3 \mathrm{kD}$ ).

The antimicrobial activity was measured by agar diffusion test (Table 1). Both Part B and Part D had marked activity against $E$. coli, $S$. aureus and $B$. subtilis. 


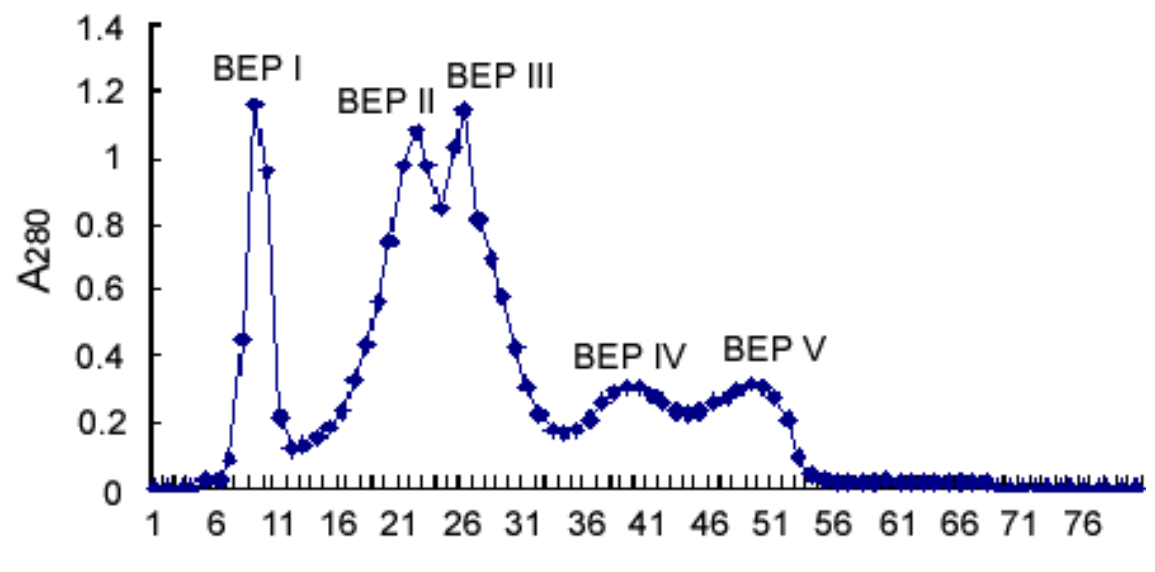

Tube Number

Figure 1. Five fractions obtained from Part $B(5$ to $10 \mathrm{kD})$. The Part $B$ of the extract was loaded onto Sephadex G-50 cartridge. Absorbance peaks were monitored at 280 $\mathrm{nm}$.

Table 2. Diameters of zone of inhibition of five fractions (BEP I to V) separated from active Part $B$ (5 to $10 \mathrm{kD}$ ) $(\mathrm{mm})(\overline{\mathrm{x}} \pm \mathrm{SD}, \mathrm{n}=3)$.

\begin{tabular}{lccccc}
\hline Type of strain & BEP I & BEP II & BEP III & BEP IV & BEP V \\
\hline S. aureus & $4.0 \pm 0.3$ & $1.2 \pm 0.1$ & $1.0 \pm 0.2$ & $0.2 \pm 0.1$ & $0.1 \pm 0.2$ \\
E. coli & $3.1 \pm 0.2$ & $2.3 \pm 0.2$ & $2.1 \pm 0.1$ & $0.4 \pm 0.1$ & 0 \\
B. subtilis & $2.8 \pm 0.2$ & $2.2 \pm 0.1$ & $1.7 \pm 0.2$ & $0.4 \pm 0.2$ & 0 \\
\hline
\end{tabular}

The antimicrobial activity was measured by agar diffusion test. The larger diameter means the more antimicrobial activity.

Part A had moderate activity against $E$. coli and $B$. subtilis, whereas the activity against Staphylococcus aureus was mild. Part $\mathrm{C}$ had no significant antimicrobial activity.

\section{Purification of antimicrobial peptides from B. exarata}

The most active Part B ( 5 to $10 \mathrm{kD}$ ) from the supernatant of tissue homogenate was loaded onto Sephadex G-50 cartridge. There were five fractions obtained, which were named BEP I, BEP II, BEP III, BEP IV and BEP V (Figure 1).

The antimicrobial activity was measured by agar diffusion test (Table 2). It showed that BEP I had marked antimicrobial activity against E. coli, $S$. aureus and $B$. subtilis. However, BEP II and BEP III had moderate activity against $E$. coli and $B$. subtilis, and had mild activity against $S$. aureus.

The fraction of BEP I, which had marked activity, was submitted to additional reverse-phase HPLC purification step on a Kromasil100-10 $\mathrm{C}_{18}$ column. Finally, three peptides were purified from this fraction, named BEP-1, BEP-2 and BEP-3 (Figure 2).

\section{Antimicrobial activity of peptides from B. exarata}

Minimal inhibitory concentration (MIC) of the three peptides purified from BEP I with reverse-phase HPLC was measured. All of the three peptides (BEP-1, BEP-2 and BEP-3) had antimicrobial activity against E. coli, $S$. aureus and $B$. subtilis, while the activity of BEP-1 was the most marked (Table 3 ). In addition, the $\mathrm{MIC}_{50}$ values of BEP-1 against three human pathogen strains ( $S$. epidermidis, E. coli and Methecillin-Resistant $S$. aureus) were 20,40 and $80 \mu \mathrm{gml}^{-1}$, and the $\mathrm{MIC}_{90}$ values were 40,80 and $160 \mu \mathrm{g} \mathrm{ml}^{-1}$ (Tables 4 and 5).

\section{DISCUSSION}

Endogenous antimicrobial peptides in marine invertebrates are exciting candidates for the development of new antimicrobial compounds, due to their broad activity spectrum and the difficulty for bacteria to develop resistance to them (Hancock and Scott, 2000; Lehrer and Ganz, 1999). The results of this study showed three novel antimicrobial peptides in the body of $B$. exarata for the first time and indicated the broad spectrum of their 


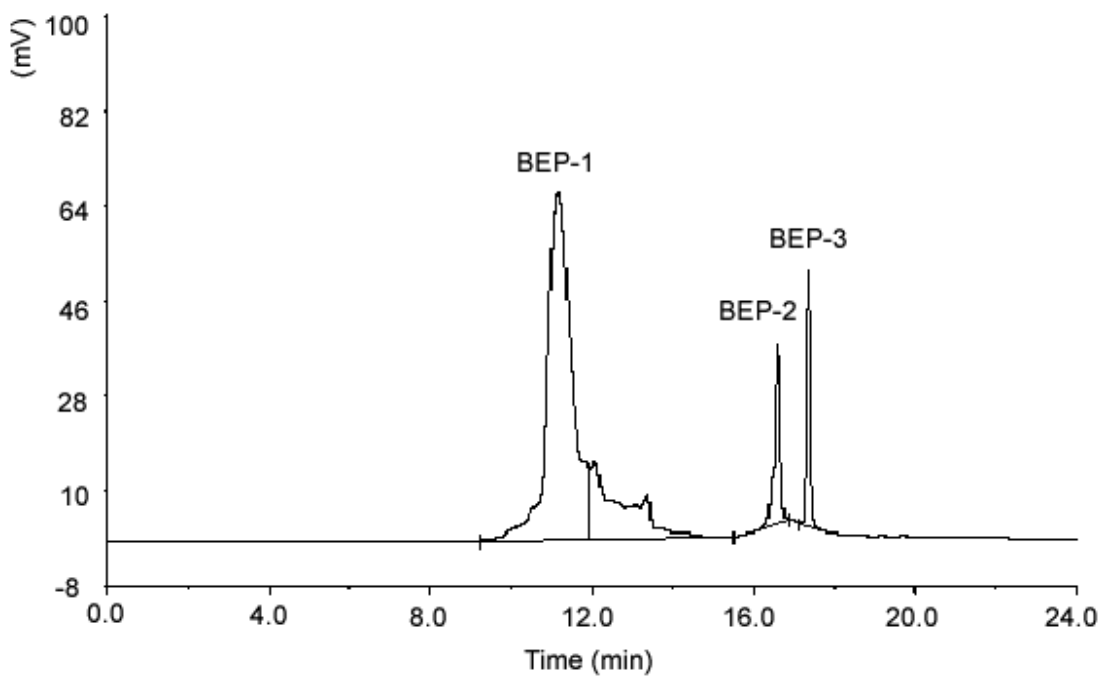

Figure 2. Reverse-phase HPLC of BEP I. The BEP I, which was isolated from the Part B (5 to $10 \mathrm{kD}$ ) of extract, was further purified on Kromasil100-10 $\mathrm{C}_{18}$ column. Absorbance peaks were monitored at $254 \mathrm{~nm}$.

Table 3. Minimal inhibitory concentration (MIC) of BEP-1, BEP-2 and BEP-3 $(\mu \mathrm{g} / \mathrm{ml})$.

\begin{tabular}{lcccc}
\hline Type of strain & BEP-1 & BEP-2 & BEP-3 & Ampicillin \\
\hline S. aureus & 20 & 80 & 40 & 10 \\
E. coli & 20 & 80 & 80 & 20 \\
B. subtilis & 40 & 160 & 80 & 20 \\
\hline
\end{tabular}

The antimicrobial activity was measured by minimal inhibitory concentration. The lower value of MIC means the more antimicrobial activity.

Table 4. Minimal inhibitory concentration (MIC) of BEP-1 against human pathogen strains $(\mu \mathrm{g} / \mathrm{ml})$.

\begin{tabular}{lccc}
\hline Type of strain (strain number) & $\mathbf{M I C}_{\text {range }}$ & $\mathbf{M I C}_{50}$ & $\mathbf{M I C}_{\mathbf{9 0}}$ \\
\hline S. epidermidis (10) & $5-80$ & 20 & 40 \\
E. coli (10) & $20-160$ & 40 & 80 \\
MRSA (10) & $20-160$ & 80 & 160 \\
\hline
\end{tabular}

The antimicrobial activity was measured by minimal inhibitory concentration (MIC). The lower value of MIC means the more antimicrobial activity. MRSA represents Methecillin-Resistant S. aureus.

antibiotic activities.

The appearance of a growing number of bacteria resistant to conventional antibiotics has become a serious problem, because of the abuse. The development of new effective antibiotics is a pressing issue. Antimicrobial peptides are not only the potent antibiotics, but also have activity of killing viruses and cancerous cells. Therefore, they may be exciting candidates as new antibacterial agents.

Recently, there are several methods used for purification of antimicrobial peptides, including bacteria inducing, tissue homogenate, gel chromatography, reverse-phase HPLC, cell culture in vitro, etc., (Charlet et al., 1996; Park et al., 1997; Liepke et al., 2001; Tomie et al., 2003; Rajaram et al., 2010). There have been many peptides isolated from marine invertebrates like Mussel and Penaeus (An et al., 2006). Mitta et al. (1999, 2000) have isolated several antimicrobial peptides from Mytilus edulis and Mytilus galloprovincialis, including mytilins, myticins and mytimycins. Mytilins have been demonstrated to be essentially active against gram-positive bacteria, and are are much less active against gram-negative bacteria. 
Table 5. Cumulative inhibitory rate of BEP-1 against human pathogen strains.

\begin{tabular}{|c|c|c|c|c|c|c|c|}
\hline \multirow{2}{*}{\multicolumn{2}{|c|}{ Type of strain (total strain number) }} & \multicolumn{6}{|c|}{ Peptide concentration $(\mu \mathrm{g} / \mathrm{ml})$} \\
\hline & & \multirow{2}{*}{$\begin{array}{l}5 \\
9\end{array}$} & \multirow{2}{*}{$\begin{array}{c}10 \\
7\end{array}$} & \multirow{2}{*}{$\begin{array}{r}20 \\
4\end{array}$} & \multirow{2}{*}{$\begin{array}{c}40 \\
1\end{array}$} & \multirow{2}{*}{$\begin{array}{c}80 \\
0\end{array}$} & \multirow{2}{*}{$\begin{array}{c}160 \\
0\end{array}$} \\
\hline \multirow{3}{*}{ Staphylococcus epidermidis (10) } & Growing strains & & & & & & \\
\hline & Inhibited strains & 1 & 3 & 6 & 9 & 10 & 10 \\
\hline & Cumulative inhibitory rate (\%) & 10 & 30 & 60 & 90 & 100 & 100 \\
\hline \multirow{3}{*}{ Escherichia coli (10) } & Growing strains & 10 & 10 & 8 & 4 & 1 & 0 \\
\hline & Inhibitory strains & 0 & 0 & 2 & 6 & 9 & 10 \\
\hline & Cumulative inhibitory rate (\%) & 0 & 0 & 20 & 60 & 90 & 100 \\
\hline \multirow{3}{*}{ MRSA (10) } & Growing strains & 10 & 10 & 9 & 7 & 4 & 1 \\
\hline & Inhibitory strains & 0 & 0 & 1 & 3 & 6 & 9 \\
\hline & Cumulative inhibitory rate (\%) & 0 & 0 & 10 & 30 & 60 & 90 \\
\hline
\end{tabular}

According to the research on antibacterial activities of extracts from seven marine organisms from Zhoushan Islands in ZheJiang province (Ma et al., 2010), we here select $B$. exarata, from which the extract has marked activity, as the resource for antimicrobial peptides. Li Y, et al. (2005) induced $B$. exarata with $E$. coli, isolated peptides from its mucus and lympha, and found marked antimicrobial activity against $E$. coli and $S$. aureus. However, the peptides from $B$. exarata are not further purified. In addition, there is still no report on purifying antimicrobial peptides directly from the meat of $B$. exarata.

All these findings confirm the idea that endogenous antimicrobial peptides in marine invertebrates could be good resources for new antimicrobial compounds. However, a more simple way to purify them seems important for the better use of these peptides in future. And it would be necessary to get more purified elements.

Here, we treated tissue homogenate of $B$. exarata with trypsin for the first time. The supernatant of this tissue homogenate was then purified with ultrafiltration, gel chromatography and reverse-phase HPLC. Finally, we got three antimicrobial peptides, named BEP-1, BEP-2 and BEP-3, from B. exarata. In addition, we found BEP-1, BEP-2 and BEP-3, especially BEP-1, have activity against E. coli, S. aureus and B. subtilis. BEP-1 was also active against human pathogen strains (S. epidermidis, $E$. coli and Methecillin-Resistant $S$. aureus). All these results indicate the broad spectrum of antibiotic activities of BEP1, BEP-2 and BEP-3. However, the structures and mechanisms of these peptides need further study.

\section{REFERENCES}

An XH, Lian JG, Li WG, Xu CH, Lu Y, Wang X, Dong J, Zhang CX, Zhang KY (2006). Isolation and purification of a novel antimicrobial peptide from Penaeus chinesis. Chin Fish Sci., 13: 1012-1016.

Brogden KA, Ackermann M, McCray PB, Tack BF (2003). Antimicrobial peptides in animals and their role in host defences. Int. J. Antimicrob. Agents, 22(5): 465-478.
Bulet P, Stöcklin R, Menin L (2004). Anti-microbial peptides: from invertebrates to vertebrates. Immunol Rev., 198: 169-184.

Charlet M, Chernysh S, Philippe H, Hetru C, Hoffmann JA, Bulet P (1996). Innate immunity. Isolation of several cysteine-rich antimicrobial peptides from the blood of a mollusc, Mytilus edulis. J. Biol. Chem., 271(36): 21808-21813.

Chen HM, Leung KW, Thakur NN, Tan A, Jack RW (2003). Distinguishing between different pathways of bilayer disruption by the related antimicrobial peptides cecropin B, B1 and B3. Eur. J. Biochem., 270(5): 911-920.

Epand RM, Epand RF (2000). Modulation of membrane curvature by peptides. Biopolymers, 55(5): 58-63.

Hancock RE, Scott MG (2000). The role of antimicrobial peptides in animal defenses. Proc. Natl. Acad. Sci. USA, 97: 8856-8861.

Lehrer RI, Ganz T (1999). Antimicrobial peptides in mammalian and insect host defence. Curr. Opin. Immunol., 11: 23-27.

Li Y, Su XR, Li TW (2005). Study on antimicrobial peptides from Bullacta exarata. J. Ocean Taiwa, 24: 145-149.

Liepke C, Zucht HD, Forssmann WG, Ständker L (2001). Purification of novel peptide antibiotics from human milk. J. Chromatogr. B. Biomed. Sci. Appl., 752(2): 369-377.

Ma JY, Si YS, Tong GZ (2010). Research on antibacterial activities of Bullacta etc. 7 marine organisms in vitro. J. Zhejiang Ocean Univ. (Nat. Sci. Ed), 29: 25-29.

Michael R (2003). Mechanism of antimicrobial peptide action and Resistance. Pharmacol. Rev., 55: 27-55.

Mitta G, Hubert F, Noel T, Roch P (1999). Myticin, a novel cysteine-rich antimicrobial peptide isolated from haemocytes and plasma of the mussel Mytilus galloprovincialis. Eur. J. Biochem., 265: 71-78.

Mitta G, Vandenbulcke F, Roch P (2000). Original involvement of antimicrobial peptides in mussel innate immunity. FEBS Lett., 486: 185-190.

Park CB, Lee JH, Park IY, Kim MS, Kim SC (1997). A novel antimicrobial peptide from the loach, Misgurnus anguillicaudatus. FEBS Lett., 411(2-3): 173-178.

Rajaram G, Manivasagan P, Gunasekaran U, Ramesh S, Ashokkumar S, Thilagavathi B, Saravanakumar A (2010). Isolation, identification and characterization of bacteriocin from Lactobacillus lactis and its antimicrobial and cytotoxic properties. Afr. J. Pharm. Pharmacol., 4(12): 895-902.

Tomie T, Ishibashi J, Furukawa S, Kobayashi S, Sawahata R, Asaoka A, Tagawa M, Yamakawa M (2003). Scarabaecin, a novel cysteinecontaining antifungal peptide from the rhinoceros beetle, Oryctes rhinoceros. Biochem. Biophys. Res. Commun., 307(2): 261-266.

Wei W, Wu XM, Li YJ (2010). Experimental methodology of pharmacology, (4) [M]. 1439-1442. 